

Cite this: Chem. Sci., 2015, 6, 7143

Received 3rd August 2015

Accepted 11th September 2015

DOI: $10.1039 / \mathrm{c} 5 \mathrm{sc} 02855 \mathrm{~h}$

www.rsc.org/chemicalscience

\section{Peripheral mechanism of a carbonyl hydrosilylation catalysed by an SiNSi iron pincer complex $\dagger$}

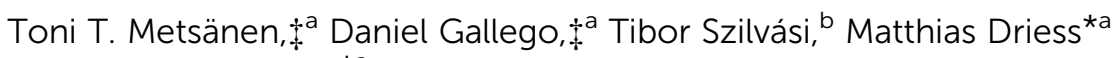 \\ and Martin Oestreich*a
}

Combined experimental and theoretical analysis of the carbonyl hydrosilylation catalysed by an iron(0) pincer complex reveals an unprecedented mechanism of action. The iron(0) complex is in fact a precatalyst that is converted into an iron(॥) catalyst through oxidative addition of a hydrosilane. Neither the hydrogen atom nor the silicon atom bound to the iron(॥) centre are subsequently transferred onto the carbonyl acceptor, instead remaining at the sterically inaccessible iron(॥) atom throughout the catalytic cycle. A series of labelling, crossover and competition experiments as well as the use of a silicon-stereogenic hydrosilane as a stereochemical probe suggest that the iron(॥) site is not directly involved in the hydrosilylation. Strikingly, it is the silyl ligand attached to the iron(II) atom that acts as a Lewis acid for carbonyl activation in this catalysis. The whole catalytic process occurs on the periphery of the transition metal. Computation of the new peripheral as well as plausible alternative inner and outer sphere mechanisms support the experimental findings.

\section{Introduction}

Iron-catalysed carbonyl hydrosilylation can be traced back to seminal reports by Brunner ${ }^{\mathbf{1}}$ but these contributions were decades ahead of their time. With few exceptions, catalyst development was focused on complexes of rare transition metals while limited progress had been made involving abundant transition metals. The pressing demand for sustainable processes finally shifted iron catalysis into the limelight, ${ }^{2}$ and several iron-based catalysts for carbonyl hydrosilylation with different ligand designs were introduced in recent years. ${ }^{3}$ The advent of these new catalysts immediately poses the question whether the mechanisms are similar to those established for rare transition-metal complexes or totally unprecedented. ${ }^{4}$ However, little detail is known about the mechanisms of action of iron complexes in catalytic hydrosilylation.

Mechanisms of transition-metal-catalysed hydrosilylations exhibit a wide variety of modes of activation. ${ }^{5}$ However, the known mechanisms are characterised as either inner sphere ${ }^{6}$

${ }^{a}$ Institut für Chemie, Technische Universität Berlin, Straße des 17. Juni 115, 10623 Berlin, Germany.E-mail: matthias.driess@tu-berlin.de; martin.oestreich@tu-berlin.de ${ }^{b}$ Department of Inorganic and Analytical Chemistry, Budapest University of Technology and Economics, Szent Gellért tér 4, 1111 Budapest, Hungary

$\dagger$ Electronic supplementary information (ESI) available: Experimental procedures and computational details, characterisation, crystallographic and quantum-chemical calculation data as well as NMR spectra. CCDC 1416378. For ESI and crystallographic data in CIF or other electronic format see DOI: $10.1039 / \mathrm{c} 5 \mathrm{sc} 02855 \mathrm{~h}$

\$ These authors contributed equally. where both the substrate and the hydrosilane are directly in contact with the metal or outer sphere ${ }^{7,8}$ where only one of the two is in contact with the metal centre. The proposed mechanisms for iron-catalysed hydrosilylations range from inner sphere mechanisms with $\sigma$-bond-metathesis-type $\mathrm{Si}-\mathrm{H}$ bond cleavage at an iron-oxygen bond ${ }^{3 k, 3 l}$ to outer sphere mechanisms with iron acting as a Lewis acid, ${ }^{3 h}$ either activating the hydrosilane or the carbonyl group.

Driess and co-workers recently introduced silylenes as $\sigma$-donor ligands in iron-based catalysis, and iron(0) complexes 1 and 2 (Fig. 1) were applied to carbonyl hydrosilylation. ${ }^{9}$ Cooperativity between the iron(0) atom and the silicon(II) hydride in $\mathbf{1}$ was postulated to be relevant in the catalytic cycle. ${ }^{9 a}$ The SiNSi iron(0) pincer complex 2 was, in turn, believed to be a precatalyst $^{\mathbf{9} \boldsymbol{b , 1 0}}$ but a detailed mechanistic analysis remained challenging. We report here the disclosure of a unique mechanism of a transition-metal-catalysed carbonyl hydrosilylation that takes place neither inner nor outer sphere but on the periphery of the metal centre without its direct involvement.
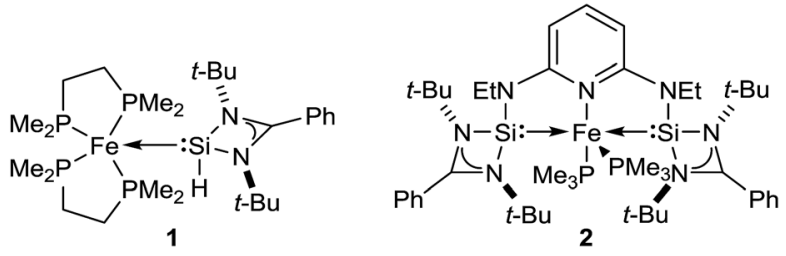

Fig. 1 Iron(0) complexes 1 (ref. 9a) and 2 (ref. 9b) introduced by Driess and co-workers. 


\section{Results and discussion}

\section{Optimisation and scope}

The SiNSi pincer complex 2 (2.5 mol\%) was found to catalyse the hydrosilylation of various acetophenones $\mathbf{3 a - 3 i}$ with silane $\mathbf{4 a}$ at elevated temperatures ${ }^{\mathbf{1 1}}$ (Table 1, entries 1-9; see the ESI $\dagger$ for the optimisation of the reaction conditions). Both electrondonating (entries 1 and 3) as well as -withdrawing (entry 6) substituents at the aryl group were tolerated with the exception of a $\mathrm{Et}_{2} \mathrm{~N}$ group in the para position (entry 2). The reaction was, however, sensitive toward steric hindrance. Substituents in the ortho position significantly lowered the yield (entries 7-9), and a 2,6-disubstituted substrate did not react (3j, entry 10$)$. Benzophenone (3k, entry 11 ) reacted readily while propiophenone and isobutyrophenone (3l and $\mathbf{3 m}$, entries 12 and 13) afforded 18 and $16 \%$ yield, respectively. Hydrosilylation of cyclopropyl substituted ketone (3n, entry 14 ) proceeded efficiently ${ }^{\mathbf{1 2}}$ (see the $\mathrm{ESI} \dagger$ for full scope).

\section{Isolation of the active catalyst}

To gain insight into the mechanism, we investigated the reaction between iron( 0 ) complex 2 and hydrosilanes $4 a-c(2 \rightarrow$ 7a-c, Scheme 1). Heating at $70{ }^{\circ} \mathrm{C}$, a new set of distinct signals appeared in the ${ }^{1} \mathrm{H}$ as well as in the ${ }^{29} \mathrm{Si}$ and ${ }^{31} \mathrm{P}$ NMR spectra. The ${ }^{1} \mathrm{H}$ NMR spectrum clearly indicated the formation of an iron hydride, and detailed NMR analysis revealed that the hydride was likely to be trans to the apical phosphine ligand. The silyl group was assigned by 2D NMR experiments to be in

Table 1 Carbonyl hydrosilylation with precatalyst $2^{a}$

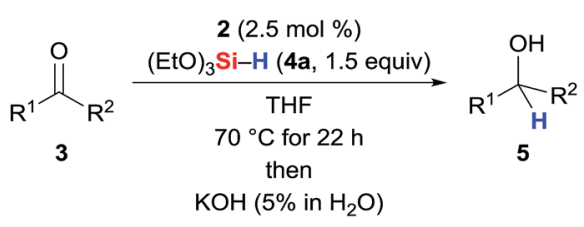

\begin{tabular}{|c|c|c|c|c|c|}
\hline Entry & 3 & $\mathrm{R}^{1}$ & & $\mathrm{R}^{2}$ & Yield of $\mathbf{5}^{b}(\%$ \\
\hline 1 & $3 a$ & & $\mathrm{X}=\mathrm{MeO}$ & $\mathrm{Me}$ & $>99(5 \mathbf{a})$ \\
\hline 2 & $3 \mathbf{b}$ & & $\mathrm{X}=\mathrm{Et}_{2} \mathrm{~N}$ & $\mathrm{Me}$ & $40(5 \mathbf{b})$ \\
\hline 3 & $3 c$ & & $\mathrm{X}=\mathrm{Me}$ & $\mathrm{Me}$ & $82(5 c)$ \\
\hline 4 & $3 d$ & & $\mathrm{X}=\mathrm{Br}$ & $\mathrm{Me}$ & $>99(5 d)$ \\
\hline 5 & $3 e$ & & $\mathrm{X}=\mathrm{H}$ & $\mathrm{Me}$ & $93(5 \mathbf{e})$ \\
\hline 6 & $3 f$ & & $\mathrm{X}=\mathrm{CF}_{3}$ & $\mathrm{Me}$ & $95(\mathbf{5 f})$ \\
\hline 7 & $3 g$ & & $\mathrm{X}=\mathrm{MeO}$ & $\mathrm{Me}$ & $70(5 \mathrm{~g})$ \\
\hline 8 & $3 h$ & & $\mathrm{X}=\mathrm{Me}$ & $\mathrm{Me}$ & $70(5 \mathbf{h})$ \\
\hline 9 & $3 \mathbf{i}$ & & $\mathrm{X}=\mathrm{Cl}$ & $\mathrm{Me}$ & $49(5 \mathbf{i})$ \\
\hline 10 & $3 \mathbf{j}$ & Mes & & $\mathrm{Me}$ & $0(\mathbf{5 j})$ \\
\hline 11 & $3 \mathbf{k}$ & $\mathrm{Ph}$ & & $\mathrm{Ph}$ & $60(5 \mathbf{k})$ \\
\hline 12 & 31 & $\mathrm{Ph}$ & & Et & $18(51)$ \\
\hline 13 & $3 m$ & $\mathrm{Ph}$ & & i-Pr & $16(5 \mathrm{~m})$ \\
\hline 14 & $3 n$ & c-Pr & & $\mathrm{Me}$ & $>99(5 n)$ \\
\hline
\end{tabular}

${ }^{a}$ Reactions were performed on $0.10 \mathrm{mmol}$ scale employing precatalyst 2 $(2.5 \mathrm{~mol} \%)$ and (EtO) $)_{3} \mathrm{SiH}$ (4a 1.5 equiv.). ${ }^{b}$ Average yield from two runs determined by GLC-MS analysis and ${ }^{1} \mathrm{H}$ NMR spectroscopy using anisole as internal standard.



Scheme 1 Identification of the catalytically active iron(II) complexes 7 from iron(0) precatalyst 2 and molecular structure of $7 \mathrm{~b}$. Hydrogen atoms except for the iron hydride are omitted for clarity.

the equatorial position trans to the pyridine ligand. We then obtained single crystals of $\mathbf{7 b}\left(\mathrm{Si}=\mathrm{Me}_{2} \mathrm{PhSi}\right)$ suitable for X-ray diffraction analysis, and that confirmed the molecular structure deduced from the NMR analysis. The structure shows a distorted octahedral iron(II) coordination environment. The hydride was located tilted toward one of the silylene donor arms deviated from the trans coordination to the $\mathrm{Me}_{3} \mathrm{P}$ ligand ( $\mathrm{P}-\mathrm{Fe}-$ H1 $\left.170.20(5)^{\circ}\right)$, a situation similar to that of known iron(II) hydride pincer complexes. ${ }^{3 h}$ The $\mathrm{Fe}-\mathrm{Si}$ bond distances 2.1509(7)/2.1715(7) $\AA$ for Fe-Si1/Si2 and 2.2986(8) for Fe-Si3 are within the range of iron silylene and silyl complexes. ${ }^{9 a, 13}$ The $t$-Bu groups encage the iron hydride with a Si1-Fe-Si2 angle far from the linearity, $144.54(3)^{\circ}$.

To validate whether the thus formed iron(II) complex 7 is the active catalyst, we measured the kinetic profiles for the hydrosilylation of $\mathbf{3 a}$ with hydrosilane $\mathbf{4 a}$ catalysed by 2 or $7 \mathbf{a}$ (Scheme 2). Conversion with 2 was only $15 \%$ after $1 \mathrm{~h}$ while the reaction had reached $74 \%$ with $7 \mathbf{a}$. The reaction with $7 \mathbf{a}$ continued with significantly higher rate reaching $86 \%$ at $4 \mathrm{~h}$ compared to only $53 \%$ with 2 . After 22 h, nearly full conversion



\begin{tabular}{ccc} 
time & $\begin{array}{c}\text { conv } \\
\text { with 2 } \\
(\%)\end{array}$ & $\begin{array}{c}\text { conv } \\
\text { with 7a } \\
(\%)\end{array}$ \\
\hline 1 & 15 & 74 \\
4 & 53 & 86 \\
8 & 80 & 94 \\
22 & 96 & 99
\end{tabular}

Scheme 2 Kinetic profiles of the iron(0) and iron(॥) complexes 2 and $7 a$ in hydrosilylation. 
is obtained for both. The greater initial rate of the catalysis with 7a strongly supports the assignment of the iron(II) complex 7 as the active catalyst.

\section{Stoichiometric experiments: hydride transfer}

With the iron(II) hydrides 7 in hand, we had a closer look at the hydride transfer. Maintaining $7 \mathbf{b}$ and deuterium-labelled hydrosilane $4 \mathbf{b}-d_{1}$ in THF at $70{ }^{\circ} \mathrm{C}$ resulted in slow H/D exchange, visible both at the silicon and iron atoms (Scheme 3, left). The stoichiometric reaction between iron(II) hydride $7 \mathbf{b}$, hydrosilane $\mathbf{4 b}-d_{1}$ ( $>95 \%$ deuteration grade), and ketone $3 \mathbf{e}$ was puzzling though (Scheme 3, right). Initially, the $\mathrm{H}: \mathrm{D}$ ratio at the methine position of silyl ether 8eb is nearly $50: 50$. However, it quickly decreases to $36: 64$ at 25\% conversion within 6 hours and then gradually increases again, returning to $50: 50$ at full conversion after a few days. Meanwhile, the corresponding reaction with partially deuterated $4 \mathbf{b}-d_{1}$ (ca. 50\% deuteration grade) yielded 8eb with little deuterium incorporation at $19 \%$ conversion $(\mathrm{H} / \mathrm{D}=90: 10)$. That ratio subsequently decreases to $78: 22$ to reach equilibrium after 24 hours. These results reveal that even though the hydride at the silicon atom in $\mathbf{4}$ is exchanging with the iron-bound hydride in 7, hydride transfer to the carbonyl carbon atom of 3 most likely occurs from the hydrosilane 4 and not from complex $7 .{ }^{14}$ Also, the reaction with partially deuterated hydrosilane indicates that the kinetic isotope effect (KIE) of the hydride transfer is significant. Precise value of the KIE could not be measured due to competing $\mathrm{H} / \mathrm{D}$ exchanges (vide infra).

The possible H/D exchange at the methine position of silyl ether 8eb was verified using 8eb- $d_{1}$ (Scheme 4 , top). Treatment of $8 \mathbf{e b}-d_{1}$ with equimolar amounts of the iron(II) hydride $7 \mathbf{b}$ indeed led to H/D scrambling. Conversely, no erosion of the enantiomeric purity was seen when subjecting enantiopure silyl ether $(S)$-8eb to the typical protocol (precatalyst 2 and hydrosilane $\mathbf{4 b}$ generate catalyst $7 \mathbf{b}$, Scheme 4 , bottom). The configurational stability of $(S)$-8eb suggests that the hydride transfer itself is irreversible, and a concerted mechanism involving frontside attack at the asymmetrically substituted carbon atom is needed to explain the hydrogen atom exchange between the catalyst and the product.



Scheme $3 \mathrm{H} / \mathrm{D}$ scrambling at the silicon and iron atoms and identification of the hydride source.

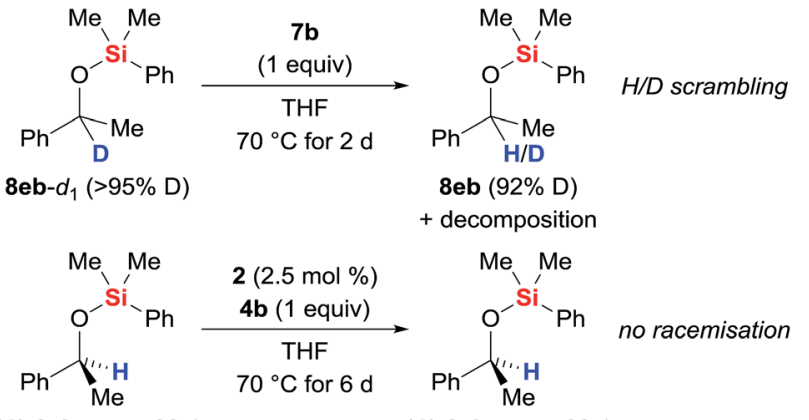

(S)-8eb: e.r. > 99:1

(S)-8eb: e.r. > 99:1

Scheme $4 H / D$ scrambling at the methine carbon atom.

These unusual scramblings were then investigated by DFT calculations. ${ }^{15}$ Both were found to proceed via a silylene-assisted concerted mechanism $\left(\mathbf{9 a}^{*}\right.$ for $\mathrm{Si}-\mathrm{H}$ and $\mathbf{1 0 a}^{*}$ for $\mathrm{C}-\mathrm{H}$, Scheme 5) where the hydride on the iron atom is first shifted to the silicon atom of the adjacent donor-stabilised silylene ligand forming a pentacoordinate silicon atom ${ }^{\mathbf{1 6}}$ while the $\mathrm{Si}-\mathrm{H}$ or $\mathrm{C}-\mathrm{H}$ bond interact with the now accessible iron centre. Both transition states are paired with their corresponding isomer where the second silylene ligand accepts the hydride. Attempts to locate the transient intermediates between the two degenerate conformations were not successful.

After the transition state, the silylene-bound hydrogen atom migrates back to the silicon and carbon atom, respectively. The activation barriers of the scrambling reactions $\left(18.5 \mathrm{kcal} \mathrm{mol}^{-1}\right.$ for $\mathrm{Si}-\mathrm{H}$ and $20.1 \mathrm{kcal} \mathrm{mol}^{-1}$ for $\mathrm{C}-\mathrm{H}$ ) are energetically accessible under the reaction conditions.

\section{Stoichiometric experiments: phosphine dissociation}

To probe the potential lability of the phosphine, we performed phosphine crossover experiments. Slow exchange of the phosphine ligand with $\left(\mathrm{CD}_{3}\right)_{3} \mathrm{P}\left(6-d_{9}\right)$ was observed (Scheme 6,



Scheme 5 Silylene-assisted H/D scrambling at the hydrosilane silicon atom $\left(9 a^{\ddagger}\right.$, left) and the methine carbon atom $\left(10 a^{\ddagger}\right.$, right); Gibbs free energies given in parentheses in $\mathrm{kcal} \mathrm{mol}^{-1} ; \mathrm{Si}=\mathrm{Si}(\mathrm{OEt})_{3}$. 

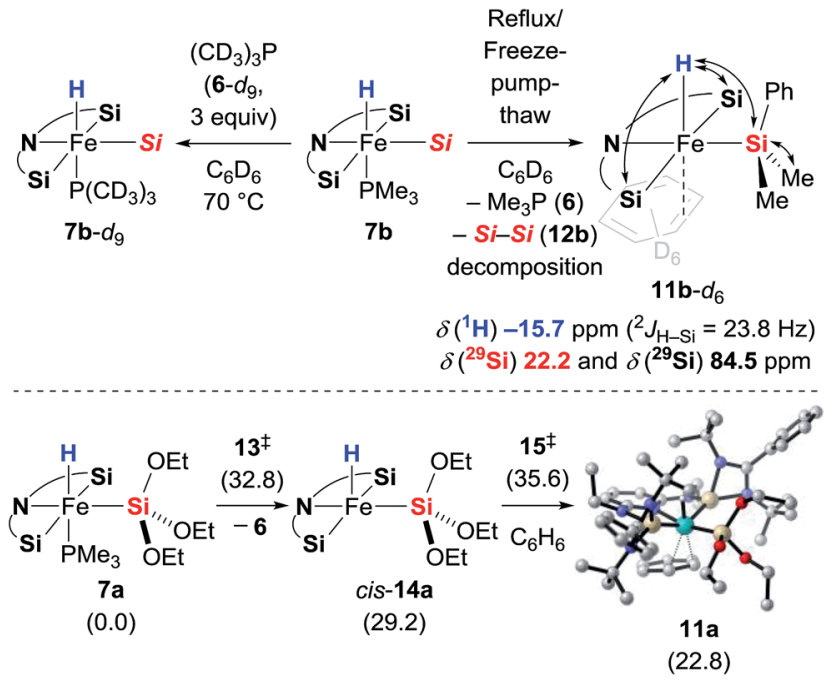

Scheme 6 Phosphine scrambling and dissociation. Double-ended arrows in $11 b-d_{6}$ show ${ }^{1} \mathrm{H},{ }^{29} \mathrm{Si} H M Q C$ NMR correlation. Gibbs free energies given in parentheses in $\mathrm{kcal} \mathrm{mol}^{-1}\left[\mathrm{Si}=\mathrm{SiMe}_{2} \mathrm{Ph}\right]$.

top left). When $\mathbf{7 b}$ was subjected to repeated reflux/freezepump-thaw cycles, we detected a new iron hydride species that was tentatively assigned as the expected phosphine-dissociated iron silyl hydride $\mathbf{1 1 b}-d_{6}$ with $\mathrm{C}_{6} \mathrm{D}_{6}$ as an $\eta^{2}$-ligand (Scheme 6, top right). The generation of this new iron compound was accompanied by formation of disilane $\mathbf{1 2 b}$ and, with longer reaction times, decomposition into a complex mixture. The role of the disilane $\mathbf{1 2 b}$ in the formation of the complex 11b remains unexplained. Unfortunately, attempts to isolate 11b- $d_{6}$ were unsuccessful. Its generation in the presence of acetophenone (3e) did not lead to the formation of the silyl ether 8eb (see the ESI $\dagger$ for details), providing further evidence against the role of $\mathbf{1 1}$ as an intermediate in the catalytic reaction. In fact, the dissociation of the $\mathrm{Me}_{3} \mathrm{P}(6)$ is significantly slower in the presence of ketone $3 \mathbf{e}$. The formation 11 was also investigated computationally (Scheme 6, bottom). Phosphine dissociation from 7 a gives energetically highly unfavoured intermediate $c i s-\mathbf{1 4} \mathbf{a}^{\mathbf{1 7}}$ that readily coordinates benzene to form adduct 11a.

It must be noted here that catalysis with Guan's related iron(II) POCOP-pincer complex is thwarted by additional $\mathrm{Me}_{3} \mathrm{P}$ (6), indicating dissociation of one of the phosphine ligands as part of the catalytic cycle. ${ }^{3 h}$ When we added $25 \mathrm{~mol} \%$ of $\mathrm{Me}_{3} \mathrm{P}(6$, 10 equiv./catalyst) to the reaction mixture, the reaction was unaffected (Scheme 7, cf. Table 1, entry 5).

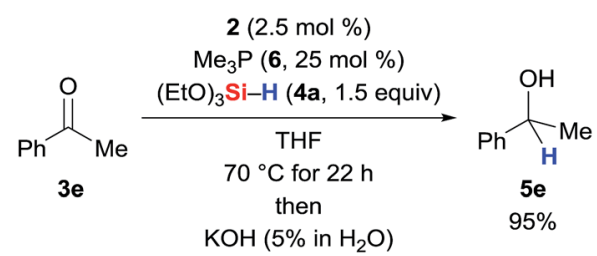

Scheme 7 Effect of excess $\mathrm{Me}_{3} \mathrm{P}$ on the catalytic activity.
As is to be expected from the above observations, the hydride complex $7 \mathbf{b}$ did not produce any silyl ether $\mathbf{8 e b}$ when reacted stoichiometrically with ketone $\mathbf{3 e}$ in the absence of a hydrosilane (Scheme 8, top left). What was fascinating though is that the silyl ligand in $\mathbf{7 b}$ also remains untouched throughout the catalysis: 7b derived from $\mathrm{Me}_{2} \mathrm{PhSiH}(\mathbf{4 b})$ catalyses the hydrosilylation of 3e with $\mathrm{MePh}_{2} \mathrm{SiH}$ (4c) with hardly any incorporation of the $\mathrm{Me}_{2} \mathrm{PhSi}$ moiety into the product; silyl ether 8ec rather than $\mathbf{8 e b}$ is formed almost exclusively (Scheme 8, right). This crossover experiment unequivocally proves that iron(II) complexes 7 are the actual catalysts, originating from oxidative addition of hydrosilanes 3 to the iron(0) complex $2 ; 2$ is a precatalyst. During the crossover experiment no changes in the characteristic signals of complex $7 \mathbf{b}$ in the ${ }^{1} \mathrm{H}$ and ${ }^{31} \mathrm{P}$ NMR spectra were detected. However, when the assumed inability of $\mathbf{7 b}$ and $\mathbf{4 c}$ to exchange their silyl groups was examined with another control experiment (Scheme 8, bottom left), we observed slow exchange with $\mathrm{ca}$. $36 \%$ conversion of $\mathbf{7 b}$ to $7 \mathbf{c}$ after $24 \mathrm{~h}$. The $\mathrm{Me}_{2} \mathrm{PhSi} / \mathrm{MePh}_{2} \mathrm{Si}$ scrambling was accompanied with formation of phosphine-dissociated, benzene-stabilised compounds 11b and 11c. Only traces of $\mathrm{Me}_{2} \mathrm{PhSiH}(\mathbf{4 b})$ were observed, indicating that the exchange ( $7 \mathbf{b}$ to $7 \mathbf{c}$ ) is in fact a side product of the decomposition rather than simple scrambling of the silyl groups.

\section{Hydrosilylation with a silicon-stereogenic hydrosilane}

With sufficient knowledge of the active catalyst, we decided to analyse the stereochemical course at the silicon atom of the reacting hydrosilane (Scheme 9). ${ }^{18}$ Catalyst $7 \mathbf{b}$ promoted the reaction between highly enantioenriched hydrosilane $\left({ }^{\mathrm{Si}} S\right)$-4d (e.r. > 95 : 5) and ketone 3 e but conversion was slow as expected from the data obtained with achiral triorganosilane $\mathbf{4 b}$ (see Table S1, entry 12 in the ESI†). After 6 days, we were able to

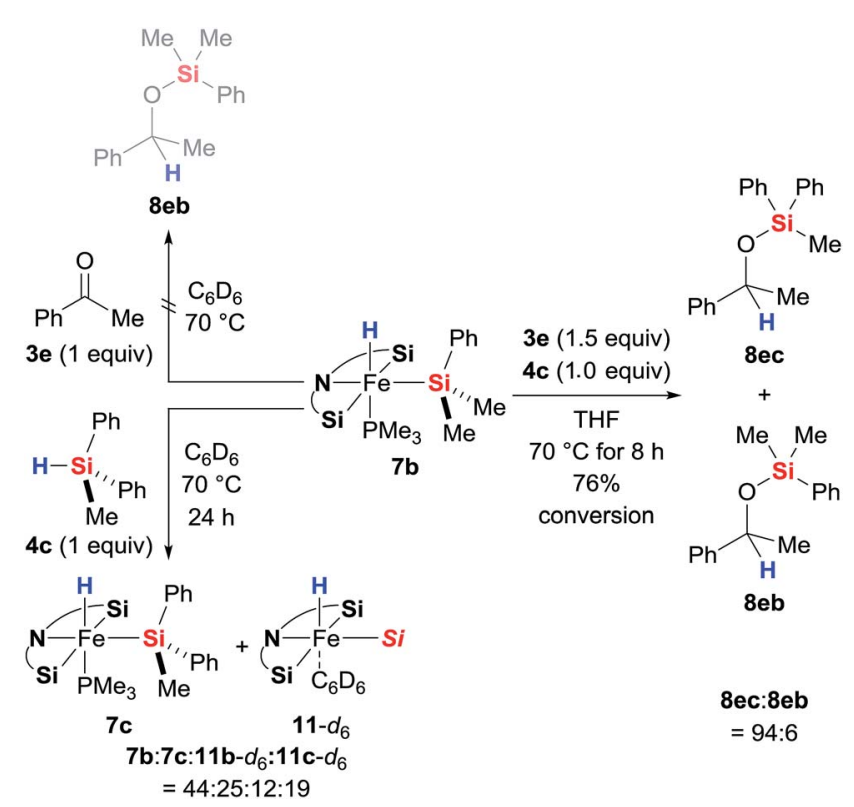

Scheme 8 Stoichiometric control and crossover experiments. 


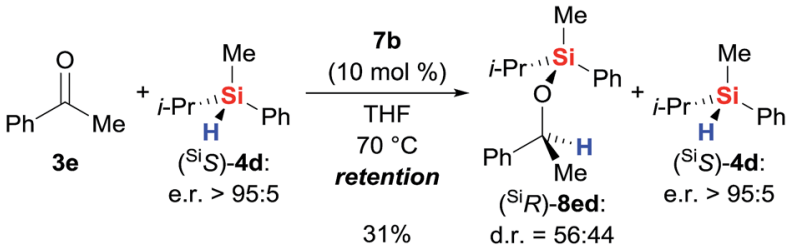



Scheme 9 Silicon-stereogenic hydrosilane as a stereochemical probe.

isolate the silyl ether $\left({ }^{\mathrm{Si}} R\right)$-8ed in $31 \%$ yield; diastereoselection was poor. The enantiomeric ratio of unreacted $\left({ }^{\mathrm{Si}} S\right)$-4d was found to be unaffected. Subsequent reductive cleavage of the $\mathrm{Si}-\mathrm{O}$ bond in $\left({ }^{\mathrm{Si}} R\right.$ )-8ed (known to proceed with stereoretention at silicon atom $\left.{ }^{19}\right)$ liberated $\left({ }^{\mathrm{Si}} \mathrm{S}\right)$-4d with overall retention of the stereochemistry at the silicon atom (e.r. > $95: 5$ ). Hence, the hydrosilylation step involves frontside attack at the silicon atom, and that makes a mechanism involving Lewis-acid activation of the hydrosilane unlikely. ${ }^{18}$

\section{DFT calculation of conventional inner and outer sphere} mechanisms $^{15}$

Based on the combined findings, we propose that the active iron(II) catalyst 7 is generated from the iron(0) precatalyst 2 by oxidative addition of hydrosilane $\mathbf{4}$ to the zero-valent iron atom (Scheme 1). As expected due to the steric congestion around the
iron(II) centre in 7a (grey box), we did not locate any structure resulting from direct insertion of the ketone $\mathrm{C}=\mathrm{O}$ group into the iron hydride 7a or the silylene ligands (not shown). Instead, we were able to find a minimum structure for the phosphinedissociated complex cis-14a (Scheme 10, left). In agreement with the experiments, cis-14a is however significantly higher in energy (29.2 kcal mol ${ }^{-1}$ relative to 7 a). The intermediate cis-14a readily coordinates THF forming the adduct 17a. This intermediate is however a resting state if not a "mechanistic dead-end". Ketone coordination to the iron centre of cis-14a gives intermediate 19oa with activated carbonyl group. The catalytic cycle is closed by an outer sphere concerted hydrosilane addition $\mathbf{2 0 o a}^{*}$ to the ketone with an activation barrier of $33.7 \mathrm{kcal} \mathrm{mol}^{-1}$.

Isomerisation of cis-14a to trans-14a was found to be strongly disfavoured, but again, ketone coordination to trans-14a lowered the energy significantly (Scheme 10, right). The following hydride transfer from 230a passes through 240a $^{\ddagger}$ (30.9 kcal $\mathrm{mol}^{-1}$ ) to afford the iron alkoxide 25oa. The silylated alcohol is released by an inner sphere silylation through $\mathbf{2 6 o a}^{\ddagger}$ with an energy barrier of $34.9 \mathrm{kcal} \mathrm{mol}^{-1}$. An alternative inner sphere mechanism could be a reductive elimination from the intermediate 250a. However, the energy barrier for the transition state $27 \mathbf{o a}^{\ddagger}$ was found to be high, and the resulting iron(0) complex 28 is energetically disfavoured. Recoordination of phosphine 6 gives iron(0) complex 29 which oxidatively adds to a silane $4 \mathbf{a}$ to form $7 \mathbf{a}$.

\section{Peripheral mechanism: support from DFT calculations}

In addition to the high energy barriers, neither outer nor inner sphere mechanisms give satisfactory fits to the experimental evidence. Hence, we looked for an adduct of $7 \mathbf{a}$ and $\mathbf{3 0}$ wherein



Scheme 10 Alternative mechanisms. Gibbs free energies given in parentheses in $\mathrm{kcal} \mathrm{mol}^{-1}\left[\mathrm{Si}=\mathrm{Si}(\mathrm{OEt})_{3}\right]$. 
the silyl group would act as a Lewis acid (Scheme 11). ${ }^{\mathbf{8 , 1 8 , 2 0}}$ Coordination of the ketone to the silyl group via low energy transition state $30 \mathbf{0 a}^{\ddagger}\left(8.1 \mathrm{kcal} \mathrm{mol}^{-1}\right)$ led to intermediate $310 a$ $\left(2.8 \mathrm{kcal} \mathrm{mol}^{-1}\right)$ with a pentacoordinate silicon atom, and the $\mathrm{C}=\mathrm{O}$ double bond being significantly elongated compared to its equilibrium distance from 1.211 to $1.251 \AA$ A indicating activation. ${ }^{21}$ Lewis pair formation is followed by coordination of hydrosilane $\mathbf{4 a}$ to the carbonyl group in 310a, and the hydrosilylation event releases 8oa through transition state $32 \mathbf{o a}^{\ddagger}$ with retention at the silicon atom. In accordance with our labelling experiments ( $c f$. Scheme 3 ), this is the ratedetermining step (14.3 $\left.\mathrm{kcal} \mathrm{mol}^{-1}\right)$. To further validate this, we conducted a competition experiment between electron-rich 3a and electron-deficient 3f (Scheme 12). The para substitution in 3 exerts a pronounced electronic effect, and $\mathrm{F}_{3} \mathrm{C}$-substituted 3f was consumed significantly faster than MeO-substituted 3a. This reactivity pattern is not unprecedented, and it has been seen previously in the activation of carbonyl compounds with silicon-based Lewis acids. ${ }^{22}$ The carbonyl carbon atom in $3 \mathbf{f}\left(\mathrm{X}=\mathrm{CF}_{3}\right)$ is more positively polarised accelerating the hydride transfer, than that of donor-substituted $3 a(\mathrm{X}=\mathrm{OMe})$. The reactivity is also in agreement with the proposed KIE based on the control reactions with deuterated silane $\mathbf{4 b}-d_{1}$ (Scheme 3 ).

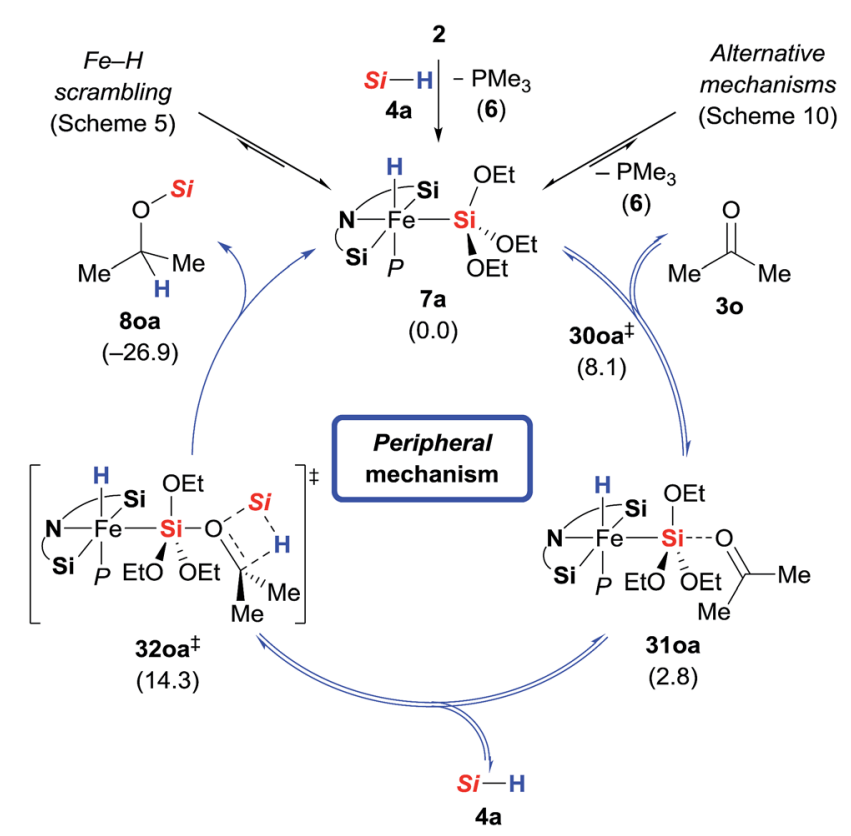

Scheme 11 Peripheral mechanism. Gibbs free energies given in parentheses in $\mathrm{kcal} \mathrm{mol}^{-1}\left[\mathrm{Si}=\mathrm{Si}(\mathrm{OEt})_{3}\right]$.

\begin{tabular}{cccccc}
$\mathbf{3 a}(\mathrm{X}=\mathrm{OMe})$ & & time & conv $\mathbf{3 a}$ & conv $\mathbf{3 f}$ \\
$(1$ equiv $)$ & see Table 1 & $\mathbf{5 a}(\mathrm{X}=\mathrm{OMe})$ & $(\mathrm{min})$ & $(\%)$ & $(\%)$ \\
\cline { 3 - 5 }+ & + & 2 & 4 & 84 \\
$\mathbf{3 f}\left(\mathrm{X}=\mathrm{CF}_{3}\right)$ & $\mathbf{5 f}\left(\mathrm{X}=\mathrm{CF}_{3}\right)$ & 5 & 21 & 99 \\
$(1$ equiv $)$ & & & 15 & 32 & 99
\end{tabular}

Scheme 12 Probing the electronic effect in a competition experiment.

\section{Conclusions}

The value of the present study is that it demonstrates, to our knowledge for the first time, an unusual case where the transition metal of a catalyst complex is not directly involved in the catalytic process. Activation of both substrate and reagent as well as the bond-forming and -breaking events happen in the ligand sphere, i.e., on the periphery of the transition metal. Coincidentally, the mechanism becomes outer sphere at silicon. ${ }^{22}$ The more conventional inner or outer sphere mechanisms do not apply to this unique catalyst.

\section{Acknowledgements}

This research was supported by the Cluster of Excellence UniCat of the Deutsche Forschungsgemeinschaft (EXC 314/2). T.S. is grateful to The New Széchenyi Plan TAMOP-4.2.2/B-10/1-20100009. M.O. is indebted to the Einstein Foundation Berlin for an endowed professorship.

\section{Notes and references}

1 For the seminal work, see: H. Brunner and K. Fisch, Angew. Chem., Int. Ed. Engl., 1990, 29, 1131-1132.

2 For reviews of iron-catalysed hydrosilylation, see: (a) K. Junge, K. Schröder and M. Beller, Chem. Commun., 2011, 47, 4849-4859; (b) M. Zhang and A. Zhang, Appl. Organomet. Chem., 2010, 24, 751-757; (c) R. H. Morris, Chem. Soc. Rev., 2009, 38, 2282-2291.

3 Selected reports include: (a) H. Nishiyama and A. Furuta, Chem. Commun., 2007, 760-762; (b) N. S. Shaikh, S. Enthaler, K. Junge and M. Beller, Angew. Chem., Int. Ed., 2008, 47, 2497-2501; (c) B. K. Langlotz, H. Wadepohl and L. H. Gade, Angew. Chem., Int. Ed., 2008, 47, 4670-4674; (d) A. M. Tondreau, J. M. Darmon, B. M. Wile, S. K. Floyd, E. Lobkovsky and P. J. Chirik, Organometallics, 2009, 28, 3928-3940; (e) T. Inagaki, L. T. Phong, A. Furuta, J.-i. Ito and H. Nishiyama, Chem.-Eur. J., 2010, 16, 3090-3096; (f) J. Yang and T. D. Tilley, Angew. Chem., Int. Ed., 2010, 49, 10186-10188; (g) A. P. Dieskau, J.-M. Begouin and B. Plietker, Eur. J. Org. Chem., 2011, 5291-5296; (h) P. Bhattacharya, J. A. Krause and H. Guan, Organometallics, 2011, 30, 4720-4729; (i) A. J. Ruddy, C. M. Kelly, S. M. Crawford, C. A. Wheaton, O. L. Sydora, B. L. Small, M. Stradiotto and L. Turculet, Organometallics, 2013, 32, 5581-5588; (j) Y. Sunada, H. Tsutsumi, K. Shigeta, R. Yoshida, T. Hashimoto and H. Nagashima, Dalton Trans., 2013, 42, 16687-16692; ( $k$ ) H. Zhao, H. Sun and X. Li, Organometallics, 2014, 33, 3535-3539; (l) Z. Zuo, H. Sun, L. Wang and X. Li, Dalton Trans., 2014, 43, 1171611722; $(m)$ T. Bleith, H. Wadepohl and L. H. Gade, J. Am. Chem. Soc., 2015, 137, 2456-2459.

4 For a mechanistic perspective, see: S. Chakraborty and H. Guan, Dalton Trans., 2010, 39, 7427-7436.

5 J. Y. Corey, Chem. Rev., 2011, 111, 863-1071.

6 For selected examples of inner sphere hydrosilylation, see: (a) I. Ojima, M. Nihonyanagi, T. Kogure, M. Kumagai, 
S. Horiuchi, K. Nakatsugawa and Y. Nagai, J. Organomet. Chem., 1975, 94, 449-461; (b) I. Ojima, T. Kogure, M. Kumagai, S. Horiuchi and T. Sato, J. Organomet. Chem., 1976, 122, 83-97; (c) G. Z. Zheng and T. H. Chan, Organometallics, 1995, 14, 70-79; (d) N. Schneider, M. Finger, C. Haferkemper, S. Bellemin-Laponnaz, P. Hofmann and L. H. Gade, Angew. Chem., Int. Ed., 2009, 48, 1609-1613.

7 For reviews of the related outer sphere hydrogenation, see: (a) O. Eisenstein and R. H. Crabtree, New J. Chem., 2013, 37, 2127; (b) R. M. Bullock, Chem.-Eur. J., 2004, 10, 2366-2374; (c) R. Noyori, M. Yamakawa and S. Hashiguchi, J. Org. Chem., 2001, 66, 7931-7944.

8 For outer sphere silane activation, see: $(a)$ X.-L. Luo and R. H. Crabtree, J. Am. Chem. Soc., 1989, 111, 2527-2535; (b) V. K. Dioumaev and R. M. Bullock, Nature, 2000, 424, 530532; (c) E. A. Ison, E. R. Trivedi, R. A. Corbin and M. M. Abu-Omar, J. Am. Chem. Soc., 2005, 127, 1537415375; (d) G. Du, P. E. Fanwick and M. M. Abu-Omar, $J$. Am. Chem. Soc., 2007, 129, 5180-5187; (e) D. V. Gutsulyak, S. F. Vyboishchikov and G. I. Nikonov, J. Am. Chem. Soc., 2010, 132, 5950-5951; (f) S. Park and M. Brookhart, Organometallics, 2010, 29, 6057-6064; $(g)$ R. Lalrempuia, M. Iglesias, V. Polo, P. J. Sanz Miguel, F. J. FernándezAlvarez, J. J. Pérez-Torrente and L. A. Oro, Angew. Chem., Int. Ed., 2012, 51, 12824-12827; (h) T. T. Metsänen, P. Hrobárik, H. F. T. Klare, M. Kaupp and M. Oestreich, $J$. Am. Chem. Soc., 2014, 136, 6912-6915; (i) M. C. Lipke and T. D. Tilley, J. Am. Chem. Soc., 2014, 136, 16387-16398; (j) M. Iglesias, F. J. Fernández-Alvarez and L. A. Oro, ChemCatChem, 2014, 6, 2486-2489.

9 (a) B. Blom, S. Enthaler, S. Inoue, E. Irran and M. Driess, J. Am. Chem. Soc., 2013, 135, 6703-6713; (b) D. Gallego, S. Inoue, B. Blom and M. Driess, Organometallics, 2014, 33, 6885-6897.
10 K. J. Szabó and O. F. Wendt, Pincer and Pincer-Type Complexes: Applications in Organic Synthesis and Catalysis, Wiley-VCH, Weinheim, 2014.

11 For state-of-the-art iron catalysts operating at room temperature, see: (a) Ref. 3f; (b) Ref. 3i; (c) Ref. 3j; (d) Ref. $3 m$.

12 No ring opening of the cyclopropyl group was observed.

13 (a) W. Yang, H. Fu, H. Wang, M. Chen, Y. Ding, H. W. Roesky and A. Jana, Inorg. Chem., 2009, 48, 5058-5060; (b) Ref. 5.

14 O. G. Shirobokov, L. G. Kuzmina and G. I. Nikonov, J. Am. Chem. Soc., 2011, 133, 6487-6489.

15 All calculations were performed at $\omega$ B97X-D/6-31G(d)[Fe:ccpVTZ] level of theory. Iron(II) complex 7a, triethoxysilane (4a), and acetone (3o) were used as model substrates. See the ESI $\dagger$ for full details.

16 The calculated structures show in fact partial opening of the NHSi rings indicating formal oxidative addition taking place on the silicon(II) centre. For a review on non-innocent ligands, see: O. R. Luca and R. H. Crabtree, Chem. Soc. Rev., 2013, 42, 1440-1459.

17 The complex cis-14a was calculated to be diamagnetic with vacant centre on the iron. The singlet-triplet gap was calculated to be only $5.1 \mathrm{kcal} \mathrm{mol}^{-1}$.

18 (a) S. Rendler and M. Oestreich, Angew. Chem., Int. Ed., 2008, 47, 5997-6000; (b) Ref. 8h.

19 M. Oestreich, G. Auer and M. Keller, Eur. J. Org. Chem., 2005, 184-195.

20 During the preparation of this manuscript a neutral silicon Lewis acid catalysis was reported: A. L. Liberman-Martin, R. G. Bergman and T. D. Tilley, J. Am. Chem. Soc., 2015, 137, 5328-5331.

21 The adduct 31 was not observed by the ${ }^{1} \mathrm{H}$ or ${ }^{31} \mathrm{P}$ NMR spectroscopy, even at lower temperatures. Also attempts to perform a Gutmann-Beckett analysis with $\mathrm{Et}_{3} \mathrm{PO}$ led to only slight broadening of the ${ }^{31} \mathrm{P}$ NMR resonance of the phosphine oxide.

22 (a) K. Müther and M. Oestreich, Chem. Commun., 2011, 47, 334-336; (b) Ref. 20. 